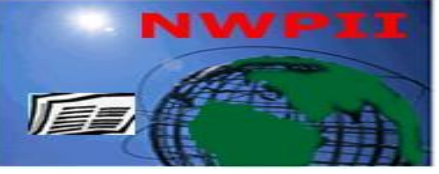

American Journal of Biomedical Sciences

ISSN: 1937-9080

nwpii.com/ajbms

\title{
Comparative Potency of Green Tea and Red Wine Polyphenols in Attenuating Staphylococcal Superantigen-Induced Immune Responses
}

\section{Teresa Krakauer}

Integrated Toxicology Division, U.S. Army Medical Research Institute of Infectious Diseases, Fort Detrick, Maryland, USA

*Corresponding Author:

Integrated Toxicology Division

USAMRIID

Fort Detrick, MD 21702-5011

USA

Phone: 301-619-4733

FAX: 301-619-2348

Email: teresa.krakauer@amedd.army.mil

Received: 15 November 2011; | Revised: 21 December 2011; | Accepted: 2 February 2012

\begin{abstract}
Proinflammatory cytokines mediate the toxic effects of staphylococcal exotoxins (SE). This study compared the potency of two polyphenols, green tea epigallocatechin gallate (EGCG) and red wine resveratrol (RES), in blocking the pro-inflammatory effects of staphylococcal enterotoxin B (SEB) and toxic shock syndrome 1 (TSST-1). Both EGCG and RES dose-dependently inhibited superantigen-stimulated Tcell proliferation with $\mathrm{IC}_{50}$ of $20 \mu \mathrm{M}$ and $30 \mu \mathrm{M}$, respectively. Both polyphenols blocked the production of interleukin $1 \beta$, interleukin 6 , tumor necrosis factor, gamma interferon, interleukin 2 , monocyte chemotactic protein 1, macrophage inflammatory protein (MIP)-1 $\alpha$, and MIP-1 $\beta$ by SE-stimulated human peripheral blood mononuclear cells (PBMC). SEB- and TSST-1-induced NF- $\kappa$ B activation in PBMC was also significantly reduced by EGCG and RES. These results suggest that polyphenols have potent immunosuppressive effects counteracting the host inflammatory cascades induced by superantigens and might be used therapeutically to mitigate the pathogenic effects of microbial superantigens.
\end{abstract}

Keywords: Anti-inflammatory, polyphenols, superantigens.

\section{Introduction}

Staphylococcal enterotoxin B (SEB) and the structurally related toxic shock syndrome 1 (TSST-1) are bacterial exotoxins and common etiological agents that cause a variety of autoimmune diseases and shock [1-3]. These exotoxins bind to both the major histocompatibility complex (MHC) class II molecules on antigen-presenting cells and specific $\mathrm{V} \beta$ regions of the T-cell antigen receptors [4-6]. The staphylococcal exotoxins (SE) are also known as superantigens because of their ability to 
polyclonally activate a considerable proportion of $\mathrm{T}$ cells [6]. Their interactions with cells of the immune system also induce a massive production of proinflammatory cytokines and chemokines [1, 2 , 7]. The cytokines, tumor necrosis factor (TNF) $\alpha$, IL-1, and interferon gamma (IFN $\gamma$ ) are pivotal mediators in superantigen-induced toxic shock [8-10]. Both TNF $\alpha$ and IL-1 have potent immuno-stimulating activities and act synergistically with IFN $\gamma$ to enhance inflammatory and immune reactions and promote tissue injury [11]. Consequently, these cytokines are pathogenic at high concentrations in vivo and are responsible for fever and toxic shock induced by SE [9. 10].

Epigallocatechin-3-gallate (EGCG), the major polyphenol in green tea, has potent antiinflammatory and anti-oxidant effects in vitro and in vivo [reviewed in 12]. Treatment with EGCG has been reported to provide therapeutic efficacy in animal models of arthritis and glomerulonephritis $[12,13]$. In vitro EGCG has multiple biological activities depending on cell type. EGCG decreased the interleukin (IL)-1induced expression of matrix metalloproteinase (MMP)-13 at $20 \mu \mathrm{M}$ and MMP-1 at $100 \mu \mathrm{M}$ in human chondrocytes at the transcriptional level [14]. At these concentrations, EGCG also blocked the IL-1-induced cartilage matrix degradation in cartilage explants and increase in $\mathrm{NF}-\kappa \mathrm{B}$ translocation and activation in chondrocytes. In a mouse macrophage cell line, millimolar concentrations of EGCG were required to attenuate lipopolysaccharide (LPS)-induced TNF $\alpha$ production and NF- $\kappa \mathrm{B}$ activation [15]. EGCG blocked SEB-disrupted epithelial cell barrier function by inhibiting cytokine release [16]. At comparable concentrations, EGCG reduced the IL1 or TNF $\alpha$-induced expression of vascular adhesion molecule-1 on endothelial cells and blocked the adhesion of monocytic cells to cytokine-activated endothelial cells [17]. In activated neutrophils, EGCG repressed ROS activity, elastase and chemokine-induced neutrophil chemotaxis [18]. At micromolar concentrations, EGCG induced vasorelaxation in rat aortic rings and increased endothelial nitric oxide synthetase [19]. EGCG is also neuroprotective as it activated the release of non- amyloidogenic protein in human neuroblastoma and rat pheochromocytoma cells at low concentrations (1-10 $\mu \mathrm{M})$ [20]. In vitro, EGCG inhibited epithelial cancer cell growth with an $\mathrm{IC}_{50}$ of $20 \mu \mathrm{M}$ through the downregulation of $\mathrm{p} 42 / \mathrm{p} 44$ and p38 MAPK [21]. Interestingly, the angiogenic factor, vascular endothelial growth factor, was also suppressed in cancer cells [21]. The chemopreventive property of EGCG was linked to its inhibition of cyclooxygenase 2 expression in colon cancer cells [22]. Redoxsensitive transcription factors, NF- $\kappa$ B and AP-1 are molecular targets for chemoprevention with EGCG [23]. In vivo, EGCG $(10 \mathrm{mg} / \mathrm{kg}$ intraperitoneally) improved hypotension and survival in a rodent model of polymicrobial sepsis [24]. The same dose of this green tea polyphenol given intravenously also reduced myocardial reperfusion injury in rats [25]. These events were associated with inhibition of I $\mathrm{B}$ kinase, AP-1, and c-Jun phosphorylation in the infracted heart. Oral administration of $0.5 \mathrm{~g} / \mathrm{kg}$ of EGCG given 2 hours before LPS prevented LPS-induced lethality in mice [15] and a reduction in serum TNF $\alpha$ was attributed to the beneficial effects of EGCG. In a diabetic nephropathy model, rats given $0.1 \mathrm{~g} / \mathrm{kg}$ of EGCG had suppressed hyperglycemia, proteinuria and lipid peroxidation, thereby reducing renal damage [26]. Thus both in vitro and in vivo, EGCG inhibits cytokine release, blocks the effects induced by proinflammatory cytokines and cytokine signaling.

Another structurally distinct polyphenol, resveratrol (3, 4', 5-trihydroxy-trans-stilbene) from red wine also shows chemoprotective effects against heart diseases, inflammation and cancers [27]. Resveratrol (RES) attenuated TNF $\alpha$-induced activation of coronary arterial endothelial cells [28] and TNF $\alpha$ induced MCP-1 in adipocytes [29]. RES downregulated gamma interferon-induced inflammatory genes by decreasing STAT-1 activation in a mouse macrophage cell line [30]. In addition, RES blocked PI3 kinase and mTOR signaling in human glioma cells $[31,32]$. RES is also neuroprotective as it prevented neurotoxicity induced by beta-amyloid in rat hippocampal neurons [33]. RES inhibited the proliferation of human renal cancer cells and exerted its antitumor effect by suppressing the expression of the VEGF 
gene [34]. RES has potent anti-oxidative effects and inhibited the production of reactive oxygen species and reactive nitrogen species during respiratory burst [35]. In lipopolysaccharidestimulated murine peritoneal macrophage, inflammatory gene expression of inducible nitric oxide synthetase and cyclooxygenase was also down-regulated [35]. RES regulated metabolism by stimulating glucose uptake in muscle cells through a mechanism involving sirtuins and AMPK [36].

Based on their similar immunomodulating properties, the relative potency of these two diverse polyphenols in attenuating staphylococcal superantigen-induced $\mathrm{T}$ cell activation and cytokine production from human peripheral blood mononuclear cells (PBMC) was evaluated.

\section{Material and Methods}

\subsection{Materials}

Purified TSST-1 and SEB were obtained from Toxin Technology (Sarasota, FL). The endotoxin content of these preparations was $<1 \mathrm{ng}$ of endotoxin/mg protein as determined by the Limulus amoebocyte lysate gelation test (BioWhittaker, Walkersville, MD). Human (h) recombinant (r) TNF $\alpha$, antibodies against hTNF $\alpha$, peroxidase-conjugated anti-rabbit $\mathrm{IgG}$, and peroxidase-conjugated anti-goat IgG were obtained from Boehringer-Mannheim (Indianapolis, IN). Human rIFN $\gamma$ and rIL-6 were obtained from Collaborative Research (Boston, MA). Antibodies against IFN $\gamma$, IL-2, and MCP-1 were obtained from BDPharMingen (San Diego, CA). Recombinant IL-2, MCP-1, MIP-1 $\alpha$, MIP$1 \beta$; antibodies against IL- $1 \beta$, IL- 6, MIP- $1 \alpha$, and MIP-1 $\beta$ were purchased from R\&D Systems (Minneapolis, MN). EGCG was obtained from Calbiochem (San Diego, CA) and dissolved in phosphate buffer saline (PBS). RES was purchased from Sigma (St. Louis, MO) and dissolved in dimethylsulfoxide. All other common reagents were from Sigma.

\subsection{Cell culture}

Human PBMC were isolated by FicollHypaque density gradient centrifugation of heparinized blood from normal human donors.
PBMC $\left(10^{6}\right.$ cells $\left./ \mathrm{mL}\right)$ were cultured at $37^{0} \mathrm{C}$ in RPMI 1640 medium supplemented with $10 \%$ inactivated fetal bovine serum in 24-well plates as previously described [37]. Cells were stimulated with SEB (200 ng/mL) or TSST-1 (200 ng/mL) for $16 \mathrm{hr}$. Varying concentrations $(2,20,50,100$ $\mu \mathrm{M})$ of EGCG or RES were added simultaneously with SEB or TSST-1. Comparisons of inhibitory activity were made with PBMC from the same donors to reduce effects due to donors' variability and experiments were repeated at least three times. Culture supernatants were collected and analyzed for IL-1 $\beta$, TNF $\alpha$, IL-6, IFN $\gamma$, IL-2, MCP-1, MIP$1 \alpha$, and MIP-1 $\beta$. Cell viability was determined by the trypan blue dye exclusion method. At the end of the experiment, cells were recovered and the number of trypan blue-positive cells was counted. Cells were $93-98 \%$ viable in the presence or absence of polyphenols with SEB using concentrations of polyphenols described.

T-cell proliferation was assayed with PBMC $\left(10^{6}\right.$ cells/well $)$, which were plated in triplicate with SEB or TSST-1 (200 ng/mL), with or without EGCG or RES, for $48 \mathrm{hr}$ at $37^{\circ} \mathrm{C}$ in 96-well microtiter plates. Cells were pulsed with 1 $\mu \mathrm{Ci} /$ well of $\left[{ }^{3} \mathrm{H}\right]$ thymidine (New England Nuclear, Boston, MA) during the last $5 \mathrm{~h}$ of culture as described previously [37]. Cells were harvested onto glass fiber filters, and incorporation of $\left[{ }^{3} \mathrm{H}\right]$ thymidine was measured by liquid scintillation.

\subsection{Measurement of cytokines and chemokines}

Cytokines and chemokines were measured by an enzyme-linked immunosorbent assay (ELISA) with cytokine- or chemokine-specific antibodies according to the manufacturer's instructions, as previously described [37, 38]. Human recombinant cytokines and chemokines (20-1000 $\mathrm{pg} / \mathrm{mL}$ ) were used as standards for calibration on each plate. The detection limit of each assay was $20 \mathrm{pg} / \mathrm{mL}$. The cytokine and chemokine data were expressed as the mean concentration $(\mathrm{pg} / \mathrm{mL}) \pm$ SD of duplicate samples.

\subsection{NF- $\kappa B$ activation assay}

NF- $\kappa \mathrm{B}$ activation was measured with a TransAM NF- $\kappa$ B kit (Active Motif, Carlsbad, CA, USA) according to the manufacturer's instructions. 
Oligonucleotides containing the NF- $\kappa \mathrm{B}$ consensus sequence (5'-GGGACTTTCC-3') were bound to a 96-well plate. Only the active form of $N F-\kappa B$ in cell extracts can specifically bind to the platebound-oligonucleotides. Nuclear extracts $(10 \mu \mathrm{g})$ containing NF- $\kappa \mathrm{B}$ protein from PBMC were added to the wells, followed by the primary antibody against p65 subunit of NF- $\kappa \mathrm{B}$ and the horseradish peroxidase-conjugated secondary antibody. Optical density was determined on an absorbance plate reader at $450 \mathrm{~nm}$.

\subsection{Data analysis}

Data were expressed as the mean \pm SD and were analyzed for significant differences by the Student's $t$-test with Stata (Stata Corp., College Station, TX, USA). Differences between polyphenol-treated and untreated control groups were considered significant if $P$ was $<0.05$.

\section{Results}

\subsection{EGCG attenuated cytokine and chemokine production from SEB-stimulated PBMC}

Based on reports that EGCG has antiinflammatory effects, we tested its potency in attentuating cytokine and chemokine production by the superantigen, SEB. Figure $1 \mathrm{~A}$ shows that EGCG blocked the production of IL-1 $\beta$, TNF $\alpha$ and IL-6 in SEB-stimulated PBMC in a dosedependent manner. EGCG at $50 \mu \mathrm{M}$ reduced the IL-1 $\beta$, TNF $\alpha$ and IL-6 levels to $20 \%, 17 \%$ and $21 \%$ in culture supernatants, respectively. The production of chemokines (MCP-1, MIP-1 $\alpha$, MIP$1 \beta$ ) were also suppressed considerably (Figure 1B). Reduction of cytokines and chemokines were statistically significant $(P<0.05)$ between SEB and SEB plus EGCG samples at concentrations of 20 to $100 \mu \mathrm{M}$. T-cell cytokines, IFN $\gamma$ and IL-2 were attenuated substantially even at a lower concentration of EGCG. At $20 \mu \mathrm{M}$ EGCG, IFN $\gamma$ and IL-2 were reduced to $1 \%$ and $4 \%$, respectively (Figure 1C). Dose response inhibition curves of EGCG were similar at both high SEB (1000 ng/mL) and low SEB (10 ng/mL) concentrations (data not shown).
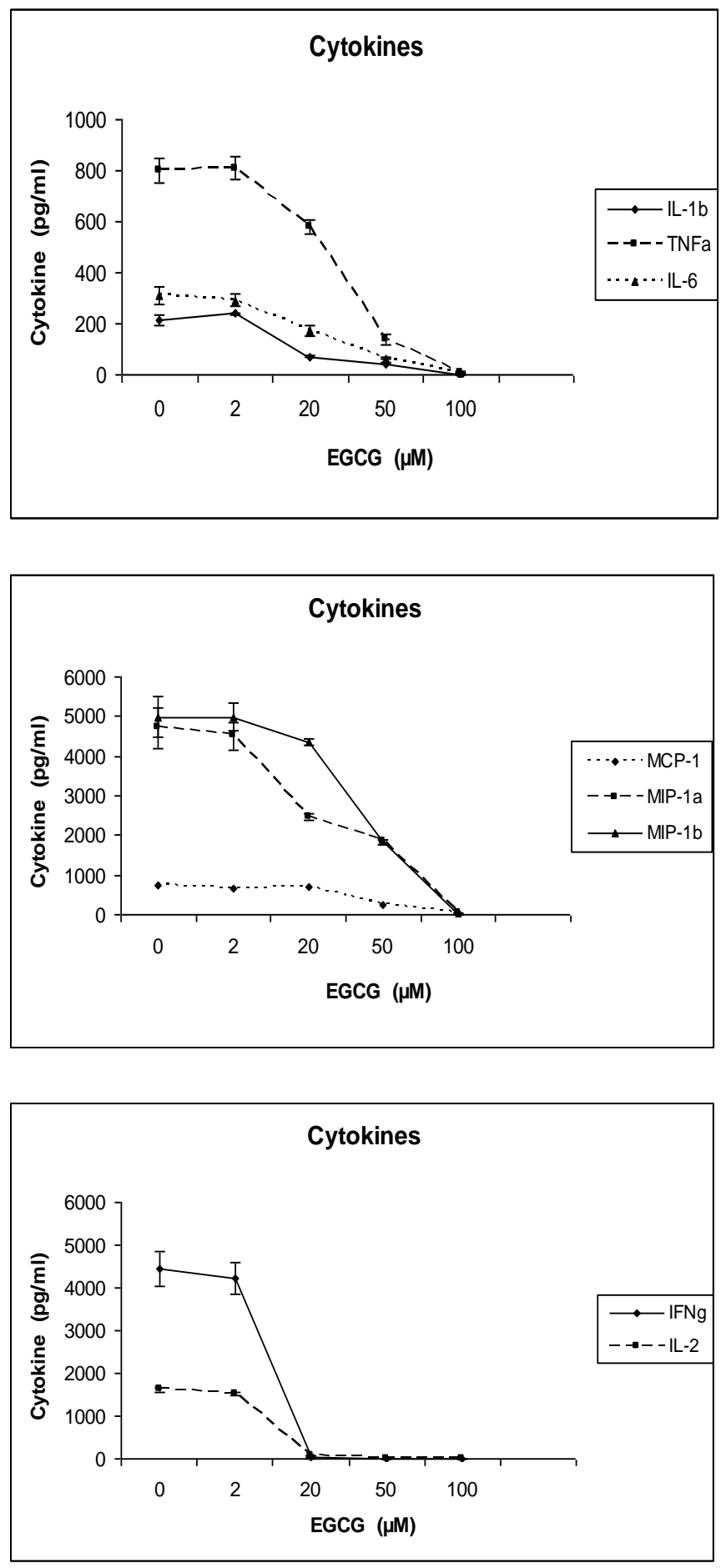

Figure 1. Dose-response inhibition of $(A) \mathrm{IL}-1 \beta$, TNF $\alpha$, and IL-6, (B) MCP-1, MIP-1 $\alpha, \operatorname{MIP}-1 \beta$ (C) IFN $\gamma$ and IL-2 production by PBMC stimulated with $200 \mathrm{ng} / \mathrm{mL}$ of SEB in the presence of various concentrations of EGCG. Values represent the mean \pm $\mathrm{SD}$ of duplicate samples and results represent three experiments. Results are statistically significant $(P$ $<0.05)$ between SEB and SEB plus EGCG samples at concentrations of 20 to $100 \mu \mathrm{M}$. 


\subsection{RES blocked cytokine and chemokine production from SEB-stimulated PBMC}

RES, another polyphenol known for its antioxidant activity, was also investigated. RES dose dependently inhibited IL-1 $\beta, \mathrm{TNF} \alpha$ and IL-6 production by SEB-stimulated PBMC, reducing IL- $1 \beta$, TNF $\alpha$ and IL- 6 by $29 \%, 65 \%$, and $51 \%$, respectively, at $50 \mu \mathrm{M}$ of RES (Figure $2 \mathrm{~A}$ ). At the same concentration of RES, the production of chemokines (MCP-1, MIP-1 $\alpha$, MIP-1 $\beta$ ) and T-cell cytokine (IFN $\gamma$ and IL-2) was blocked to the same extent (Figure 2B and 2C). Higher concentrations of RES blocked the production of these cytokines and chemokines more completely. Inhibition of cytokines and chemokines by RES were statistically significant $(P<0.05)$ between SEB and SEB plus RES samples at concentrations of 20 to $100 \mu \mathrm{M}$. RES did not affect the viability of the cells over the concentration range used in these studies $(2-100 \mu \mathrm{M})$, as confirmed by trypan blue dye exclusion test. Thus comparatively, using the same cell culture system and PBMC from the same blood donors, EGCG was more potent in blocking TNF $\alpha$, IFN $\gamma$ and IL-2 than RES.

\subsection{EGCG and RES inhibited TSST-1 induced cytokines and chemokines}

Figure 3 compares the inhibition by $50 \mu \mathrm{M}$ EGCG and RES on cytokine and chemokine production by PBMC cultures stimulated with another staphylococcal exotoxin, TSST-1. The level of inhibition of TSST-1-stimulated cells by EGCG and RES was similar to that of SEB suggesting that both polyphenols are effective inhibitors of superantigen-activated inflammatory pathways. The suppressive effects of EGCG were higher on T-cell cytokines IFN $\gamma$ and IL-2. EGCG was also a stronger inhibitor than RES using TSST-1-stimulated cells.

\subsection{EGCG and RES inhibited superantigen- induced $\mathrm{T}$-cell proliferation}

Because superantigen polyclonally activates $\mathrm{T}$ cells, the effect of the polyphenols, EGCG and RES on SE-induced T-cell proliferation was next investigated. Figure 4 shows that both EGCG and RES potently inhibited SEB- and TSST-1stimulated $\mathrm{T}$-cell proliferation in a dose-dependent manner; achieving $6 \%$ and $16 \%$ inhibition at 50 $\mu \mathrm{M}$ of EGCG and RES, respectively. The inhibition of T-cell proliferation by either EGCG or RES were statistically significant $(P<0.05)$ between superantigen and superantigen plus polyphenol (20-100 $\mu \mathrm{M})$ samples.
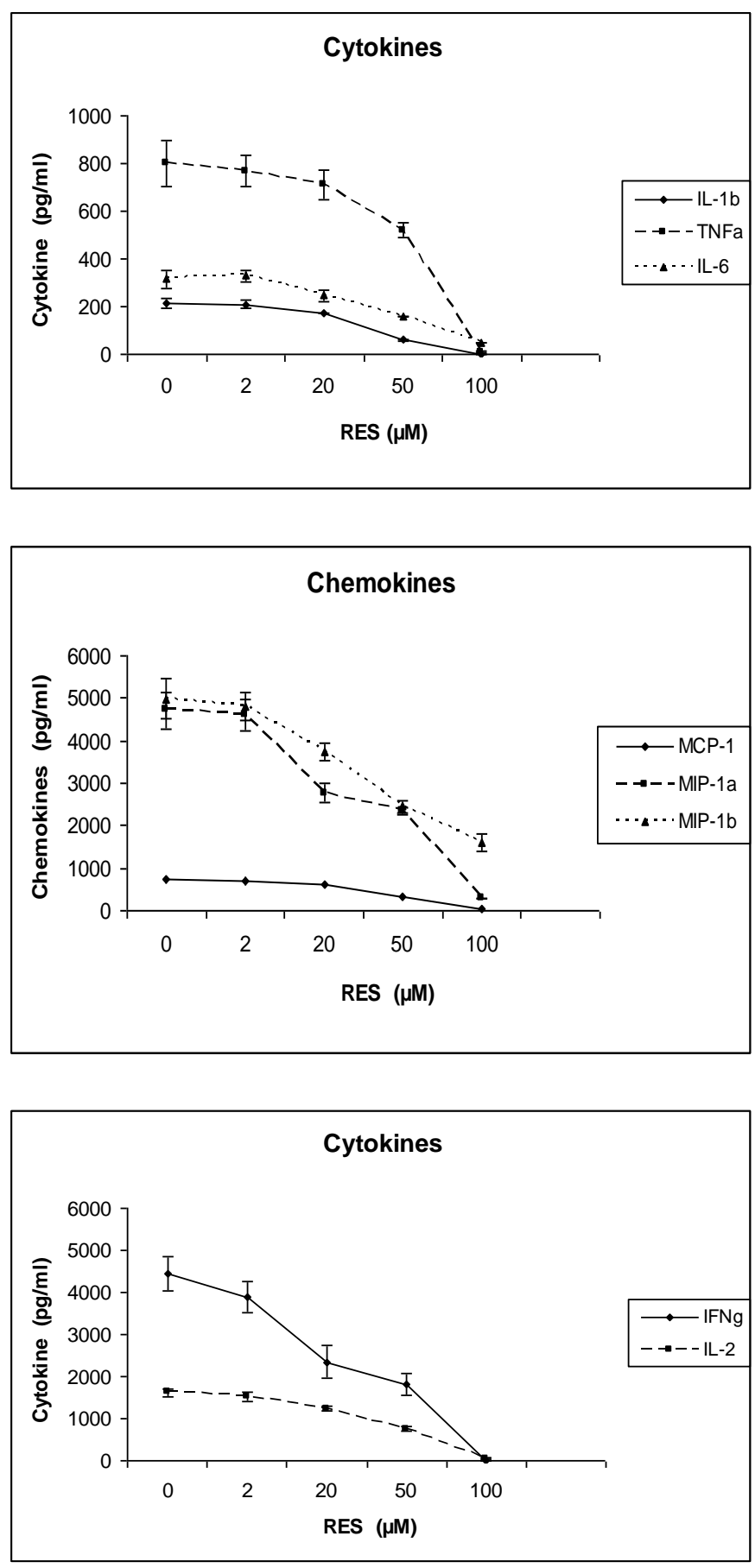

Figure 2. Dose-response inhibition of $(A)$ IL-1 $\beta$, $\mathrm{TNF} \alpha$, and IL-6, (B) MCP-1, MIP-1 $\alpha$, MIP-1 $\beta$ (C) IFN $\gamma$ and IL-2 production by PBMC stimulated with $200 \mathrm{ng} / \mathrm{mL}$ of SEB in the presence of various concentrations of RES. Values represent the mean \pm 
SD of duplicate samples and results represent three experiments. Results are statistically significant $(P$ $<0.05)$ between SEB and SEB plus RES samples at concentrations of 20 to $100 \mu \mathrm{M}$.
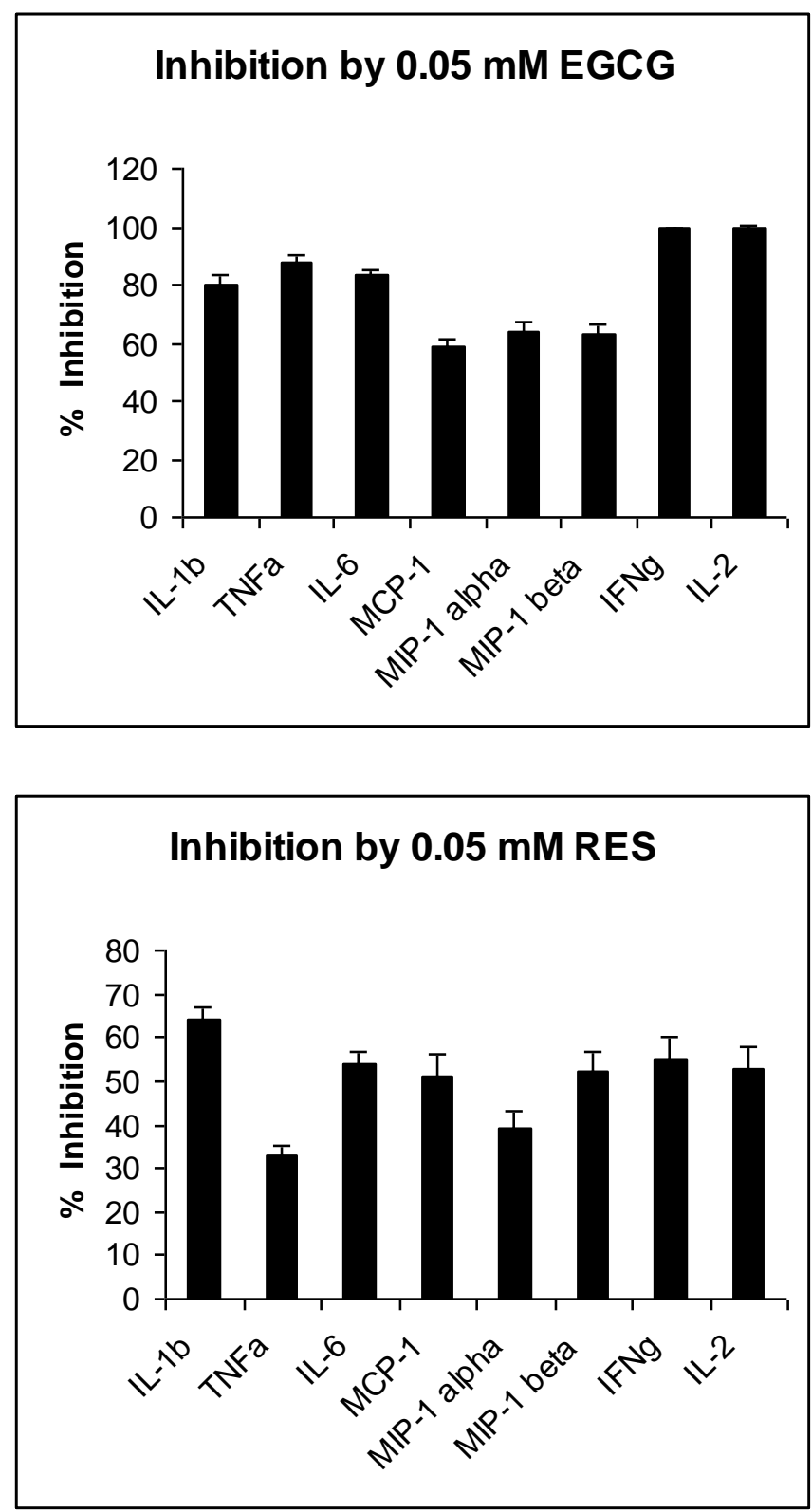

Figure 3. Inhibition of (A) IL- $1 \beta, \mathrm{TNF} \alpha$, IL-6, MCP1 , MIP-1 $\alpha$, MIP-1 $\beta$, IFN $\gamma$ and IL-2 production by PBMC stimulated with $200 \mathrm{ng} / \mathrm{mL}$ of TSST- 1 in the presence of $50 \mu \mathrm{M}$ EGCG, (B) IL-1 $\beta$, TNF $\alpha$, IL-6, MCP-1, MIP-1 $\alpha$, MIP-1 $\beta$, IFN $\gamma$ and IL-2 production by PBMC stimulated with $200 \mathrm{ng} / \mathrm{mL}$ of TSST-1 in the presence of $50 \mu \mathrm{M}$ RES. Values represent the mean \pm SD of three samples and results represent three experiments. Results are statistically significant $(P$ $<0.05$ ) between TSST-1 and TSST-1 plus EGCG and TSST-1 plus RES.
Proliferation

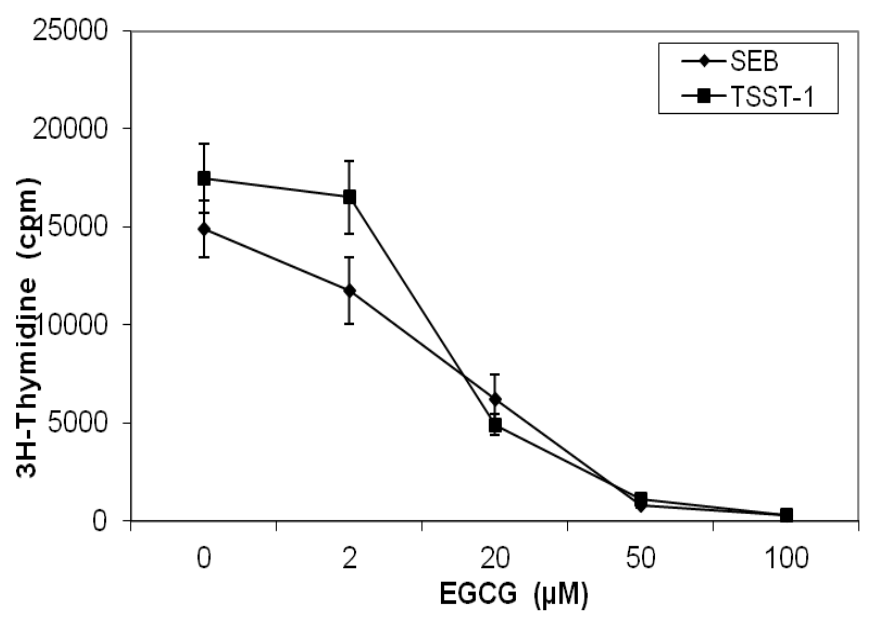

Proliferation

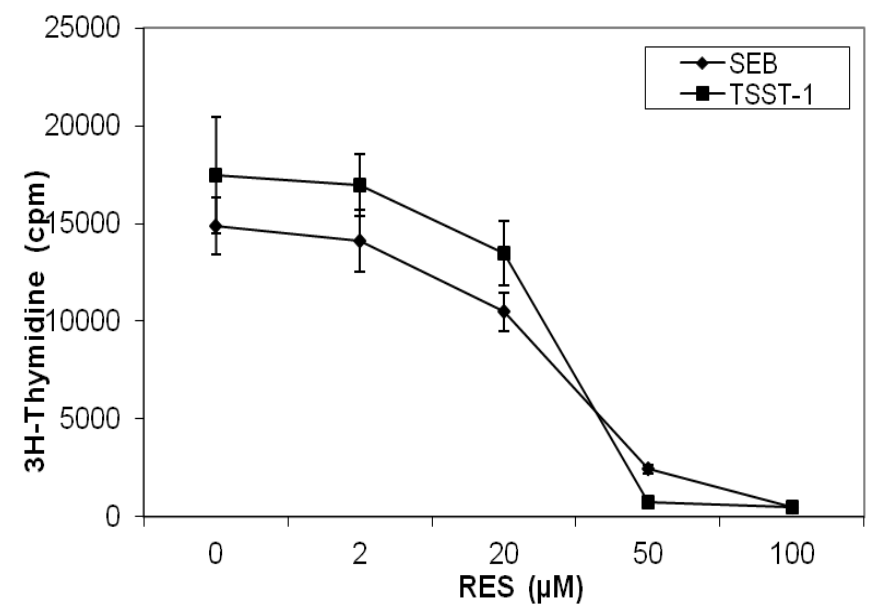

Figure 4. Inhibition of T-cell proliferation in PBMC stimulated with $200 \mathrm{ng} / \mathrm{mL}$ of SEB or TSST-1 in the presence of various concentrations of $(A)$ EGCG, $(B)$ RES. Values represent the mean $\pm \mathrm{SD}$ of triplicate samples and results represent three experiments. Results are statistically significant $(P<0.05)$ between stimulant (TSST-1 or SEB) and stimulant plus polyphenol $(20-100 \mu \mathrm{M})$ samples.

\subsection{EGCG and RES blocked NF-кB activation in superantigen-stimulated PBMC}

The transcription factor $\mathrm{NF}-\kappa \mathrm{B}$ is a key regulator of inflammation and acts downstream of many cell surface receptors including MHC class II molecules and toll-like receptors. The effects of EGCG and RES on NF- $\kappa \mathrm{B}$ activation were next investigated. Cell extracts from SEB-treated 
PBMC in the presence or absence of EGCG or RES were prepared and $\mathrm{NF}-\kappa \mathrm{B}$ activation was measured by DNA-binding on oligonucleotidecoated plates. As shown in Figure 5, EGCG blocked SEB-induced increase in activated NF- $\kappa \mathrm{B}$ to $27 \%$ at $50 \mu \mathrm{M}(P<0.05)$ whereas RES reduced NF- $\kappa \mathrm{B}$ activation to $39 \%(P<0.05)$. Thus the inhibitory dose of both EGCG and RES was directly correlated to the potency of these polyphenols in reducing cytokine and chemokine production.

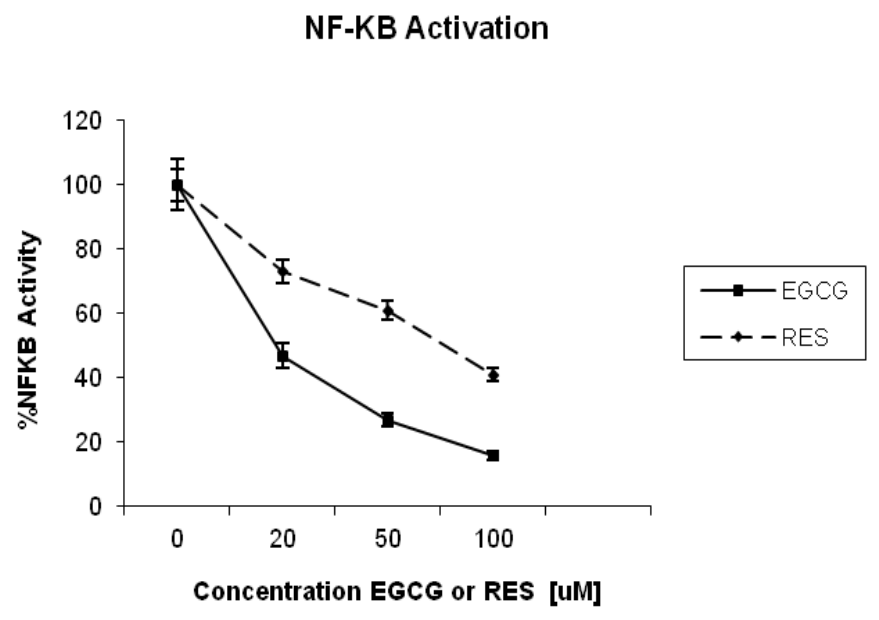

Figure 5. Inhibition of $\mathrm{NF}-\kappa \mathrm{B}$ activation in PBMC stimulated with $200 \mathrm{ng} / \mathrm{mL}$ of SEB by varying concentrations of $(A)$ EGCG and $(B)$ RES. Values are the mean $\pm \mathrm{SD}$ of duplicate samples from three experiments. Results are statistically significant $(P$ $<0.05$ ) between SEB and SEB plus polyphenols from $20-100 \mu \mathrm{M}$.

\section{Discussion}

Toxic shock caused by staphylococcal superantigens is a serious disease with a high mortality rate, and so far, successful treatment remains elusive despite great efforts invested in drug development. Anti-inflammatory and immunosuppressive therapeutics represent a potentially useful treatment by targeting many downstream signaling pathways affecting multiple cytokines and chemokines. The results presented here indicate that green tea EGCG and red wine RES suppressed the induction of proinflammatory cytokines and chemokines by TSST-1- and SEB- stimulated human PBMC. The production of these mediators by monocytes/macrophages and $\mathrm{T}$ cells in response to superantigens initiates leukocyte activation and migration, contributing directly to inflammation and tissue injury associated with shock. The effect of EGCG and RES was more pronounced on $\mathrm{T}$ - cell proliferation. EGCG also had more inhibitory effect on the T- cell cytokines, IL-2 and IFN $\gamma$ whereas higher doses were required to suppress other cytokines and chemokines to the same extent. RES also dose dependently reduced the production of chemokines MCP-1, MIP- $1 \alpha$, and MIP-1 $\beta$ and all cytokines from superantigenstimulated PBMC. This indicates that polyphenols inhibited both cytokines and chemokines produced in vitro by both $\mathrm{T}$ cells and monocytes in response to superantigens.

Attenuated $\mathrm{T}$ cell activation with decreased elaboration of key proinflammatory cytokines by EGCG and RES suggests that polyphenols from green tea and red wine may prove useful in treating superantigen-induced shock. Our studies showed that both EGCG and RES suppress a broad range of cytokines and chemokines, induced by superantigens, suggesting that these polyphenols target several intracellular signaling pathways. One prominent pathway is the transcriptional activation of $\mathrm{NF}-\kappa \mathrm{B}$ which regulates the expression of inflammatory cytokines, cyclooxygenase 2 , and cell adhesion molecules [39]. This interference of NF- $\kappa \mathrm{B}$ activation by both polyphenols likely accounts for their immunosuppressive effects. Our result is in agreement with previous observations that polyphenols downregulate NF- $\kappa \mathrm{B}$ activity which accounts for their pleiotropic effects $[12,27]$. In conclusion, due to the broad spectrum of cytokines antagonized, and based on its beneficial therapeutic effects in autoimmune diseases, polyphenols may prove useful as therapeutics for the treatment of superantigen-induced toxic shock.

\section{Acknowledgments}

The research described herein was sponsored by the Defense Threat Reduction Agency. The technical assistance from Marilyn Buckley is greatly appreciated. 
The views expressed in this publication are those of the author and do not reflect the official policy or position of the Department of the Army, the Department of Defense, or the U.S. Government.

\section{References}

1. Kotzin, B.L.; Leung, D.Y.M.; Kappler, J.; Marrack P.A. Superantigens and their potential role in human disease. Adv. Immunol., 1993, 54, 99-166.

2. McCormick, J.K.; Yarwood, J.M.; Schlievert, P.M. Toxic shock syndrome and bacterial superantigens: an update. Ann. Rev. Microbiol., 2001, 55, 77-104.

3. Fraser, J.; Arcus, V.; Kong, P.; Baker, E.; Proft, T. Superantigens-powerful modifiers of the immune system. Mol. Med. Today, 2000, 6, 125-132.

4. Mollick, J.A.; Chintagumpala, M.; Cook, R.G.; Rich, R.R. Staphylococcal exotoxin activation of $\mathrm{T}$ cells. Role of exotoxin-MHC class II binding affinity and class II isotype. $J$. Immunol., 1991, 146,463-468.

5. Baker, M.D.; Acharya, K.A. Superantigens: Structure, function, and diversity. In: Krakauer, T., Ed.; Superantigen Protocols, Humana Press, 2003; pp1-31.

6. Choi, Y.; Kotzin, B.; Hernon, L.; Callahan, J.; Marrack, P.; Kappler, J. Interaction of Staphylococcus aureus toxin "superantigens" with human T cells. Proc. Natl. Acad. Sci. USA, 1989, 86, 8941-8945.

7. Krakauer, T. Immune Response to staphylococcal superantigens. Immunol. Res., 1999, 20, 163-173.

8. Jupin, C.; Anderson, S.; Damais, C.; Alouf, J.E.; Parant, M. Toxic shock syndrome toxin 1 as an inducer of human tumor necrosis factors and gamma interferon. J. Exp. Med., 1988, 167, 752-761.

9. Miethke, T.; Wahl, C.; Heeg, K.; Echtenacher, B.; Krammer, P.H.; Wagner, H. T cellmediated lethal shock triggered in mice by the superantigen SEB: critical role of TNF. $J$.
Exp. Med., 1992, 175, 91-98.

10 . Stiles, B.G.; Bavari, S.; Krakauer, T.; Ulrich, R.G. Toxicity of staphylococcal enterotoxins potentiated by lipopolysaccharide: major histocompatibility complex class II molecule dependency and cytokine release. Infect. Immun., 1993, 61, 5333-5338.

11. Krakauer, T.; Vilcek, J.; Oppenheim, J.J. TNF family cytokines, chemokines and other pro- or anti-inflammatory cytokines. In: Paul W.E., Ed.; Fundamental Immunology. $4^{\text {th }}$ ed. Lippincott-Raven Publishers, 1999, pp783811.

12 . Singh, R.; Akhtar, N.; Haqqi, T.M. Green tea polyphenol epigallocatechin-3-gallate: inflammation and arthritis. Life Sci., 2010, 86, 907-918.

13. Peng, A.; Ye, T.; Rakhela, D. et al. The green tea polyphenol (-)-epigallocatechin-3-gallate ameliorates experimental immune-mediated glomerulonephritis. Kidney Int., 2011, 80, 601611. doi: 10.1038/ki.2011.121.

14. Ahmed, S.; Wang, N.; Lalonde, M.; et al. Green tea polyphenol epigallocatechin-3gallate (EGCG) differentially inhibits interleukin-1 beta-induced expression of matrix metalloproteinase- 1 and -13 in human chondrocytes. J. Pharmacol. Exp. Ther., 2004, 308, 767-73.

15. Yang, F.; de Villiers, W.J.; McClain, C.J.; Varilek, G.W.; et al. Green tea polyphenols block endotoxin-induced tumor necrosis factor-production and lethality in a murine model. J. Nutr., 1998, 128, 2334-2340.

16. Watson, J.L.; Vicario, M.; Wang, A.; et al. Immune cell activation and subsequent epithelial dysfunction by Staphylococcus enterotoxin B is attenuated by the green tea polyphenol (-)-epigallocatechin gallate. Cell. Immunol., 2005, 237, 7-16.

17. Ludwig, A.; Lorenz, M.; Grimbo, N.; et al. The tea flavonoid epigallocatechin-3-gallate reduces cytokine-induced VCAM-1 expression and monocyte adhesion to endothelial cells. Biochem. Biophy. Res. Comm., 2004, 316, 659-665.

18. Dona, M.; Alica, I.; Calabrese, F.; et al. Neutrophil restraint by green tea: inhibition of inflammation, associated angiogenesis, and 
pulmonary fibrosis. J. Immunol., 2003, 170, 4335-4360.

19. Alvarez, E.; Campos-Toimil, M.; JustinianoBasaran, H.; Luqnier, C.; Orallo, F. Study of the mechanisms involved in the vasorelaxation induced by (-)-epigallocatechin-3-gallate in rat aorta. Br. J. Pharmacol., 2006, 147, 269-280.

20 . Levites, Y.; Amit, T.; Mandel, S.; Youdim, M.B. Neuroprotection and neurorescue against Abeta toxicity and PKC-dependent release of nonamyloidogenic soluble precursor protein by green tea polyphenol (-)-epigallocatechin3-gallate. FASEB J., 2003, 17, 952-954.

21 . Spinella, F.; Rosano, L.; Di Castro, V.; et al. Green tea polyphenol epigallocatechin-3gallate inhibits the endothelin axis and downstream signaling pathways in ovarian carcinoma. Mol. Cancer Ther., 2006, 5, 14831492.

22. Peng, G.; Dixon, D.A.; Muga, S.J.; et al. Green tea polyphenol (-)-epigallocatechin-3gallate inhibits cyclooxygenase-2 expression in colon carcinogenesis. Mol. Carcin., 2006, 45, 309-319.

23. Surh, Y.J. NFкB and AP-1 as molecular targets for chemoprevention with EGCG, a review. Environ. Chem. Lett., 2006, 4, 137141.

24 . Wheeler, D.S.; Lahni, P.M.; Hake, P.W.; et al. The green tea polyphenol epigallocatechin-3gallate improves systemic hemodynamics and survival in rodent models of polymicrobial sepsis. Shock, 2007, 28, 353-359.

25 . Aneja, R.; Hake, P.W.; Burroughs, T.J.; et al. Epigallocatechin, a green tea polyphenol, attenuates myocardial ischemia reperfusion injury in rats. Mol. Med., 2004, 10, 55-62.

26. Yamabe, N.; Yokozawa, T.; Oya, T.; Kim, M. Therapeutic potential of (-)-epigallocatechin 3O-gallate on renal damage in diabetic nephropathy model rats. J. Pharm. Exp. Ther., 2006, 319, 228-236.

27. Pirola, L.; Fröjdö, S. Resveratrol: one molecule, many targets. IUBMB Life, 2008, 60, 323-332.

28. Csiszar, A.; Smith, K.; Labinskyy, N.; Orosz, Z.; Rivera, A.; Ungvari, Z. Resveratrol attenuates TNF- $\alpha$-induced activation of coronary arterial endothelial cells: role of NF- $\kappa \mathrm{B}$ inhibition. American Journal of Physiology-Heart and Circulatory Physiology, 2006, 291, H1694-H1699.

29.Zhu, J.; Yong, W.; Wu, X. et al. Antiinflammatory effect of resveratrol on TNF- $\alpha$ induced MCP-1 expression in adipocytes. Biochem. Biophy. Res. Commun. 2008, 369, 471-477.

30. Chung, E.Y.; Kim, B.H.; Hong, J.T.; Lee, C.K.; Ahn, B.; Nam, S.Y.; Han, S.B.; Kim, Y. Resveratrol down-regulates interferon- $\gamma$ inducible inflammatory genes in macrophages: molecular mechanism via decreased STAT-1 activation. J. Nutr. Biochem., 2011, 22,902909. doi: 10.1016/j.jnutbio.2010.07.012.

31 . Frojdo, S.; Cozzone, D.; Vidal, H.; Pirola, L. Resveratrol is a class IA phosphoinositide-3kinase inhibitor. Biochem J., 2007, 406, 511518.

32 . Jiang, H.; Shang, X.; Wu, H.; Gautam, S.C.; Al-Holou, S.; Li, C., et al. Resveratrol downregulates PI3K/Akt/mTOR signaling pathways in human U251 glioma cells. J. Exp. Ther. Oncol., 2009, 8, 25-33.

33. Han, Y.S.; Zheng, W.H.; Bastianetto, S.; Chabot, J.G.; Quirion, R. Neuroprotective effects of resveratrol against beta-amyloidinduced neurotoxicity in rat hippocampal neurons: involvement of protein kinase C. $\mathrm{Br}$. J. Pharmacol., 2004, 141, 997-1005.

34. Yang, R.; Zhang, H.; Zhu, L. Inhibitory effect of resveratrol on the expression of the VEGF gene and proliferation in renal cancer cells. Mol. Med. Rep., 2011, 4, 981-983. doi: 10.3892/mmr.2011.511.

35. Leiro, J.; Alvarez, E.; Arranz, J.A.; Laguna, R.; Uriarte, E.; Orallo, F. Effects of cisresveratrol on inflammatory murine macrophages: antioxidant activity and downregulation of inflammatory genes. J. Leukoc. Biol., 2004, 75, 1156-1165.

36. Breen, D.M.; Sanli, T.; Giacca, A.; Tsiani, E. Stimulation of muscle cell glucose uptake by resveratrol through sirtuins and AMPK. Biochem. Biophys. Res. Comm., 2008, 374, 117-122.

37. Krakauer, T. Inhibition of toxic shock syndrome toxin- induced cytokine production and $\mathrm{T}$ cell activation by 
interleukin 10, interleukin 4, and dexamethasone. J. Infect. Dis., 1994, 172, 988992.

38. Krakauer, T. Induction of CC chemokines in human peripheral blood mononuclear cells by staphylococcal exotoxins and its prevention by pentoxifylline. J. Leukoc. Biol., 1999, 66, 158164.
39. Ben-Neriah, Y.; Karin, M. Inflammation meets cancer, with NF- $\mathrm{B}$ as the matchmaker. Nat. Immunol., 2011, 12, 715-723. doi: $\underline{10.1038 / \text { ni.2060. }}$ 